\title{
Inheritance Status and Strategy of Aken Playing and Singing of Kazak Nationality
}

\author{
Xiao Liyan", ${ }^{1, *}$ Li Jia ${ }^{2}$ \\ ${ }^{1}$ College of Teacher'S Education, Nanyang Institute of Technology, Nanyang, Henan, China \\ International College, Krirk University, Bangkok, Thailand \\ ${ }^{2}$ College of Music, Shanxi Normal University, Shanxi, China \\ *Corresponding author
}

Keywords: Akon playing and singing, inheritance, present situation, strategy.

\begin{abstract}
Xinjiang, this vast land, its music is diverse and diverse, xinjiang Kazak music is also rich and colorful, want to have a deep understanding of the Kazakh national music must understand the living status of the Kazakh people, want to understand the living status of the Kazakh people must understand the kazakh folk poetry. Kazakh traditional art is rich and diverse, among which Akan playing and singing of Kazakh nationality is widely spread in this nation. In May 2006, it was selected as one of the first "Representative works of oral and intangible heritage of Humanity" in China. Aken playing and singing is known as the "poetry nation" in the Kazakh people. It is a long folk traditional art form of the Kazakh people. It is a playing and singing form combining the musical instrument "Dongbula" with folk music, and it is one of the most important forms of entertainment for the Kazakh people on the grassland. In this paper the characteristics and the existing of Ken bards nomadic life habits is not stable, lack of education value, the original cultural erosion and the shortage of funds into real problem made a systematic analysis and comb, in order to further the protection of ethnic culture and heritage development, the implementation of the scientific and effective countermeasures, so as to provide some theoretical reference for Ken bards inheritance protection.
\end{abstract}

\section{Introduction}

The music of Xinjiang is diverse and diversified. Aken playing and singing is known as the "poetry nation" of The Kazakh people in Xinjiang, and it is a time-honored traditional folk art form of the Kazakh people. Aken playing and singing is a combination of "Dongbula" and folk songs. According to research, this art form appeared in the 10th century, but it is still widely spread among the Kazakhs. This paper discusses aken playing and singing of Kazakh nationality, analyzes its musical characteristics and performance characteristics, and sorts out and studies the inheritance of Aken playing and singing. Through this study, it is expected to bring some reference for the protection and development of traditional folk art. 


\section{Overview of Kazak Akon playing and singing}

\subsection{Overview of Akon's playing and singing}

Kazakh akon playing and singing is the most traditional art. Every year, herdsmen from five lakes and all over the world wear costumes with national characteristics and come to the blooming grassland with dongbula singing and dancing. Its form of expression is mainly reflected in improvisation. Permeate the impromptu playing and singing in daily production and life.Lyrics, can reflect the enthusiasm of the Kazakh people unrestrained character, reflects the foot of the Tianshan mountain a generation of grassland children's cultural deposits.

\subsection{The form of Akon playing and singing}

Akon playing and singing can be divided into three forms: impromptu singing, akon playing and singing and Akon duet.The first is improvising poetry. This form is a form to show full of classics, which is different from the ancients who recite poems about wine under the moon. They must write on the spot and blurt out the words, so this form needs to be tempered for numerous times. In the second way, Akan players sing while playing with dongbula in their arms. This kind of playing and singing is mostly singing traditional long narrative poems and interesting life. Third, duet, there are two people singing in pairs, there are many people singing in pairs. It is characterized by improvisation, which has the nature of match song. It combines men and women with singing and poetry, which not only enriches the charm of life, but also loses a touch of liveliness.

\subsection{The musical characteristics of Akon's playing and singing}

\subsubsection{Tone characteristics}

Kazakh Aken plays and sings in many modes, the most basic of which is the national pentatonic scale, which often adopts the seven-tone scale mode. The artistic creation of national music usually incorporates the musical elements of Western European countries, but pentatonic or seven-tone scale are the same. Folk songs mostly adopt the style of yu tone and gong tone, which plays an important role in forming a new style of music with national characteristics. In Akan playing and singing, feather notes (Si) are more common than hui notes (FA). This practice also led to more ethnic style in Akon's music creation. Of these modes, the most common are natural major and natural minor. There are many beautiful songs played in nature major such as "Mayella", "Young Birds".Nature minor is no exception: "Avaguri", "Swallow" and so on.

Akon sang the first song for the beginning and end of the echo type of tone, interval for four, five jump. Its melody is beautiful but not rough, in the mold, expansion, repetition of the technique of mutual transformation. Modality is often used for temporary modulation or alternation, and there are also jumps .The huying tone is an obvious feature of Kazak folk songs, which often appears in the beginning and sentence of songs, and sometimes in the end of sentences. Such is the case with the song "Mayella" in terms of structure and mode.

Compared with Akon's playing and singing of short minor notes, the tunes of popular songs nowadays are relatively longer, and the musical structure has also changed compared with the past. The structure is not as neat as the antithesis in the past, and the sense of rhythm is relatively more complex and diverse. One of the most typical structural ways is to add refrain on the basis of the passage. The refrain is often the expansion and variation of the theme part of the repeated evolution, 
generally the anaphora for the expansion of the development of a single.

For the creation of rap songs, the form of structure is more varied, using the creation techniques of comparison, question and answer and direct narration, and choosing lyrics that are easy to catch the mouth and endowed with good wishes. This rap song integrates the allegro performance characteristics of western music in the form of creation, adding a beautiful sense of rhythm in music song creation, making the song sound passionate and heroic.

\subsubsection{The buckling characteristics}

In terms of the selection of beat, 3/8 beat is usually the main beat, which adds the theme and narration of music art and makes the song more appealing in singing. Akan playing and singing consists of single meter and compound meter, usually using compound meter in melody. The basic meter has duple meter and triple meter, and there are various variations. For example, in the song "Under the Silver Moon", the first part (A) is in e-flat major, in 3/4 time, with A short introduction of 2 bars. The melody is full of passion and ups and downs. This section is a folded section, a non-square integral section, and a triplet section, consisting of three phrases A, B and B1.These three phrases, the first two (a, B) are contrast phrases, and the third phrase repeats b with obvious changes, as if they are parallel. This combination of three phrases is very interesting. The music moves into the middle after a short five-bar interlude, which aims to change to a minor of the same name. The middle type of the work is the single theme of the extension of the middle. The middle passage shifts to e flat minor of the same name. The structure is exactly the same as that of the first part, and it is also composed of three phrases. The passage adopts the same minor key with strong contrast in melody, but it is consistent with that of the first part in twist. This extended writing method is often used in lyric songs. After an eight-bar interval, the music enters the recapitulation and switches back to E-flat major. So that the accompaniment and the main melody match in an orderly way.

\section{Investigation on the inheritance of Akon playing and singing}

Through a lot of Aken songs of kazaks, we can see that these artistic achievements are created according to the needs of their own national life, including their blessing to the local people, but also implied their shadow of the local people's living habits. Now we can get a glimpse of their national culture from their folk songs, so the Kazakh aken playing and singing art is an indispensable part of our traditional national culture. Ethnic music has its obvious ethnic cultural characteristics. Although it has the characteristics of other ethnic cultures, it is just this multi-ethnic cultural characteristics that highlights the diversity of kazakh ethnic music. It is on this basis that kazakh folk music is spread and progress, resulting in kazakh folk music can communicate with other ethnic cultures in China and mutual penetration, mutual learning.

By means of questionnaire survey, 300 questionnaires for residents and 300 questionnaires for students were distributed to 3 ethnic communities and 5 schools in Mulei County. A questionnaire survey was conducted for the migrating residents and students to understand the status quo of Akon playing and singing in Mulei County in detail, and the following data analysis was obtained.

\subsection{To investigate the living conditions of herdsmen}

Kazakhs were once steppe nomads. Life habits are also changing. With the development of urbanization, China's urbanization process is accelerating. China's rural population is gradually moving into cities, and the urban population is increasing, while the rural population is decreasing. Most herdsmen go to the city to struggle, buy a house in the city, and finally settle down in the city, 
many herdsmen have moved into high-rise buildings. The Kazakhs are also moving farther and farther to oases and yurts, disrupting their original living environment. Thus it can be seen that the semi-closed Kazak nationality has long been further and further away from their former nomadic life, and the herdsmen's life and production mode are changing rapidly. Akan playing and singing also wants to separate from its most primitive form.

\subsection{Investigation on the status quo of incorporating folk music into music teaching}

Analysis: Whether it is the development of modern education or the development of The Times, or the change of educational concepts, the lack of folk music education, piano learning as hobby training, are changing rapidly. More parents think that training children to learn piano, can let children set up a correct aesthetic sense, feel and experience the wonderful music. Dancing is mostly for girls. The cultivation of good temperament and culture is influenced by art. There are only a few groups learning this folk music, and the current classroom does not pay enough attention to folk music, which is not well absorbed in the classroom. Teachers rationalize and incorporate ethnic characteristics according to the characteristics of children's physical and mental development, causing children to cultivate ethnic art lovers in school.

\subsection{Investigation on the current situation of cultural heritage and inheritors}

Akon playing and singing is a fading part of intangible cultural heritage. With the acceleration of the modernization process, the influence of foreign culture is constantly occurring. The production, lifestyle and cultural ecology of the survival and development of intangible cultural heritage have undergone great changes, and the frequency of daily production and social activities of some intangible cultural heritage is decreasing day by day. Many intangible cultural assets with scientific value in history and culture are disappearing gradually, or even facing extinction due to the death of inheritors. Intangible cultural assets are becoming more and more valuable. Such as kazak nationality embroidery, kazak ethnic costumes, traditional marriage and folk craftsmanship called naan, milk a knot in one's interesting folk activities: horse, sheep diao, wrestling, and so on are dying: black cook's dance music, kazak language, "Stan" rap music, impromptu, dobro folk musical performances, wide cloth transcribing "kwai in accordance with the" play, Ken humai contest is gradually by people The forgotten.

Aken playing and singing as an intangible cultural heritage, its inheritance is extremely low, almost unknown in the folk. Intangible cultural heritage of traditional folk culture heritage rely mostly on oral teaching, some only on oral transmission, with the development of modern science and technology, the progress of the society, make full use of existing non-material cultural heritage has no obvious economic benefits, plus a new generation of young people lack of interest in the national traditional folk culture, as a result, Many folk artists get too old or die, without heirs, and the intangible cultural heritage is lost.

\subsection{Current situation of cultural protection funds}

Insufficient protection, insufficient cultural funds, "please reiterate, light protection". At present, there is no emphasis on the protection of intangible cultural heritage into the annual financial budget. Many old audio and video tapes cannot be re-recorded and protected, and the necessary activity protection cannot be carried out normally. 


\section{Akon playing and singing inheritance status quo attribution}

\subsection{Changes in people's living environment}

In history, kazak was once a nomadic people who migrated to live on the grassland. Habits are also changing. In recent years, the state has launched many long-term policies, and great achievements have been made in poverty alleviation. The life and production of various ethnic groups are all moving in step with the modern society. The Kazakhs are also moving away from oases and yurts, breaking their original living environment. People use ethnic embroidery and other handicrafts to increase their income and live in clean and beautiful new houses.

Thus it can be seen that such a good life has made the semi-closed Kazak people far away from their former nomadic life. At present, most herdsmen have stable dwellings, and the herdsmen's life and production mode are changing rapidly, so akan playing and singing is gradually separated from its most primitive form.

\subsection{Lack of attention to education}

The country has popularized the use of Mandarin for communication, and parents have ignored the importance of their own national language. At the same time, to some extent, parents ignore the skills and ability development of their own language, which is not conducive to the cultivation of excellent talents in akan playing and singing.

Most schools set up to learn piano, pop music and other all the current Musical Instruments and songs, this national characteristics of playing and singing is also buried, no one to explore it. With the trend of The Times, young people are fond of pursuing a foreign culture. Schools do not carry forward ethnic music culture, lack of ethnic music culture into the music class. The inherent status of the national music is not highlighted in the teaching, resulting in inadequate education and cultural heritage inheritance.

\subsection{The loss of original culture}

At present, according to relevant data, there are about 80 Kazakh folk songs in different forms widely spread in Mulei County. Once kazak music becomes elite culture, it will develop towards media culture and commercial culture in some aspects. This tendency is reflected in a number of pioneering experimental works that are turning the transformation and innovation of form into a commercial trick under the implicit effect of the exchange and benefit principles of the market economy. The most primitive cultural atmosphere of Akan playing and singing has been deteriorated. Nowadays, "Akon playing and singing" performing arts activities are increasingly decreasing among the people. Some activities often have to be made against their will to meet the market demand of consumer fashion, or wear masks that do not belong to the public, so that the original culture is destroyed to cater to The Times, as shown in:

The young people who love and care for Akon have not absorbed the essence of the old Akon.

The knowledge level of the new Akans has not reached a superb skill, lack of deep study and exploration. Thus, there is a lack of original works.

quite a part of the old Akon is not well protected, relatively speaking, slowly exquisite technology also fell silent.

These are the causes of cultural loss. 


\subsection{Insufficient capital investment}

The protection of cultural relics is a weak quality, which cannot be separated from the support and massive investment of people from all walks of life. The lack of capital investment has become one of the main problems in our transformation. Should we rely entirely on the transformation of national financial input to maintain the transformation, or should we look for funders from multiple channels?

For example, a few years ago, the recording and videotape of "Akon playing and singing" preservation records were very backward and were retained by aging equipment. At present, we want to restore the early data into modern digital carrier, which is convenient and can be retained in a variety of ways. But this work needs human and material resources from all aspects, and more importantly, financial support. There is also a shortage of funds for a big Akan concert, and the need to attract a large infusion of capital from investors.

There is a museum dedicated to akon and his music. Also set up relevant departments to protect. More open some artistic performance activities to promote and attract guests, are indispensable.

\section{An effective strategy to protect Akon's playing and singing status}

With the gradual acceleration of the pace of people's life and the diversified development of the structure of social life, we should not only keep the national character but also pay attention to absorb the beneficial factors of advanced culture. The non-cultural heritage should be valued and protected so as to be transmitted to children and grandchildren. Based on the current development status of Akon playing and singing, "Akon playing and singing", as a part of intangible cultural heritage, should start with the following strategies in reviewing its development history:

\subsection{Call for government role and coordination mechanism.}

It calls for the leading role of local government, reasonable distribution of work, participation of various departments to do vigorous publicity, so that more people know the existence of Akon and its own values. Mobilize relevant departments to protect folk culture work, clear division of labor, abide by their duties, to promote and develop.

We will increase the publicity of Akon playing and singing in various variety shows. We will hold two large-scale "Akon playing and singing Conferences" every year to invite Akon artists from all walks of life to have a discussion, so that the culture of our nation can be brought into the vision of popular culture and carried forward.

The local government should pay attention to the protection of grassland ecology. The original performance venue is on the qingqing grassland, where the original atmosphere is protected and the original appearance reappears.

\subsection{The school strengthens the dissemination of educational culture}

Starting from education, as an important carrier of information, language plays an increasingly important role in the historical process of promoting economic development and social progress. On the basis of Chinese learning, parents should strengthen the spoken and written language of the Kazakh nationality, and train their children to explore and protect the cultural heritage of the ethnic group.

On the other hand, school education. Bilingualism is an inevitable phenomenon of human development. Schools specially set up "entering the class of folk music" to let ethnic minorities spread their own culture. In primary and secondary schools, we will develop playing and singing interest classes to cultivate playing and singing enthusiasts from an early age, and start with the most 
realistic education to solve the inheritance problem.

\subsection{Inheriting folk art and cultivating professional talents}

The use of local university platform to promote the traditional culture, introducing local intangible cultural heritage of local university campus cultural activities, organize special shows which plays an instrument and sings akon, expand the influence, and try to be included in the local university public art courses system, using a variety of media and communication platform of college teaching, can spread akon culture, It also allows students who like Akan culture to get more learning opportunities and learn, absorb, inherit and develop in the local music education environment.

Strengthen leadership by utilizing the leading role of the Cultural and Radio Bureau. Create performance opportunities through various channels or set up special swimming singing crew to perform in the countryside. Akon playing and singing as an intangible cultural heritage has attracted many folk music lovers to learn and communicate.

According to the survey: in the middle of December, 2007, yili normal college organization and set up in xinjiang according to research, for those who have a talent for composing and singing "Ken", the relevant departments for the protection, and provides the basic living expenses for them, to ensure that they can get people to create.

\subsection{Promote the use of tourism "treasure into wealth"}

"Aken playing and singing" can also become a part of tourism resources, waiting for research and development. From the perspective of Xinjiang geology, good mountains and good waters are everywhere. Using the platform to promote the performance to meet with world Ken bards, through various platforms, such as: with the rapid development of social modernization, informatization and networking, music produced by the technology, the new carrier, TV sets, recorders, CD, mp3, broadcast, video, net ease cloud raise public awareness of it, it's got a lot of potential economic value.

Culture is the guide of tourism, tourism is the disseminator of culture, and the two complement each other. Driving the integration of culture and tourism industry to advance, not only helps the development of cultural industry, but also promotes the tourism industry step by step, which greatly meets the cultural needs of tourists, drives the increase of economic amount, also highlights the characteristics and development of traditional Chinese culture, and improves the status of culture in society. Every year, Xinjiang holds many "Akan Playing and Singing" conferences to attract tourists and investors from all over the world. Then we hold activities to attract tourists, and at the same time, we can show our ethnic characteristics of clothing, delicious food, and strange handicrafts made by herdsmen. In this way, he earned a great deal of income and contributed greatly to the preservation of akon's playing and singing materials. Tourism culture integration!

\section{Conclusion}

To sum up, I conducted relevant interviews, observations and surveys during my practice. There are many deficiencies in the inheritance of Akon playing and singing. Also according to current situation of inheritance in the nomadic way of life, education, the lack of subsequent researchers, the problem of insufficient capital investment put forward some effective strategies, in the process of inheriting Ken attacks not only should take the essence to the dregs, to comply with the time development needs, so as to realize kazak akon attacks in music art is a splendid treasure, According to the needs of people living with The Times change, raising the level of appreciation, unprecedented changes have taken place in the different eras, took a different form of expression, the different stages of the kazak excellent folk art, a combination of the complete, more fully embody the life 
characteristics of kazak, protecting the valuable and representative works of art. In order to make a contribution to intangible cultural heritage.

\section{References}

[1] Wang Shengbing, Sha Yanqin, "Mulei Kazak Autonomous County Annals" Xin, (2003) 021

[2] Wang Jianchao. Music from the Field - A Case Study of Traditional Music of Uygur and Kazak [C] Xinjiang Normal University, 2006

[3] Tong Zhongming Customs song about Life Etiquette of Kazak people. Research on National Literature, 1987 (6) : 66-70

[4] Gao PAN. Glory and Decline of Local Folk Art__Investigation and Analysis of xinye Huaishu [R]. Nanyang Institute of Technology 2005.

[5] WANG Liang. Research Status and Theoretical Thinking of Akan Playing and Singing of Kazak [J]. Xinjiang Normal University.

[6] WANG Jianchao. The Inheritance and dissemination of Festivals and Kazakh Traditional Music culture ---- Take two Festival Art Performances in Kizilorda city as an example [J] Journal of Xinjiang University of Arts, 2013 (2) :23 